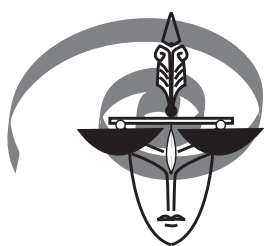

\title{
EUROPEAN
}

Volume $9 \cdot 2015 \cdot$ Number 3 (33)

DOI: 10.1515/ep-2015-0006

Ryszard Jaworski

University of Wrocław

Wrocław, Poland

\section{Charts of the 'Innocent' Subjects in the Searching Peak of Tension Tests}

Key words: Chart interpretation, Scoring, Peak of Tension, Searching Peak of Tension

\section{Introduction}

The previous study presented my observations concerning the practice of Searching Peak of Tension test (SPOT) application during the examination of the subjects later proved to be perpetrators (Jaworski 2015). I concluded that physiological parameters of the subjects show their great emotional activation caused by the SPOT questions; moreover, activation increased when the test was repeated, which was substantiated by the increased pulse rate, high diastolic blood pressure, and changing rate and depth of breathing. I put forth a hypothesis that physiological parameters of the innocent subjects (groundlessly suspected) will display less activation, which will tend

\footnotetext{
*rjaworsk@prawo.uni.wroc.pl
} 
to decrease in the second chart. The SPOT charts for the perpetrators would differ from those of the innocent subjects in two aspects:

- the degree of activation in the first SPOT application in comparison with average 'resting' parameters,

- the change of the activation level in consecutive SPOT charts.

If this hypothesis were confirmed, SPOT charts might become an additional diagnostic premise during a CQT examination and provide an auxiliary function. As mentioned above, additional diagnostic premises could be helpful during an examination of subjects suspected of murder when there is a problem with formulating control questions so that their content is as significant emotionally as that of the relevant questions.

This argument is quoted primarily by the opponents of the CQT. They also claim that physiological parameters of innocent people may indicate great activation, but their emotions may be triggered by causes other than concealing their participation in a murder: questioning their positive relationship with the deceased, indignation at groundless suspicions, fear of an error which an expert can make. While the practice does not confirm these reservations, they cannot be ignored, especially if there is an opportunity to acquire the parameters useful for correcting a possible error.

In my experience, the SPOT is very rarely administered in the examination of the innocent subjects. This has resulted from the preliminary assessment of the CQT chart: I resigned from the application of the SPOT when the subjects' reactions to the control questions in the CQT were greater than the reactions to the relevant questions. I applied the SPOT only in a few cases, when more than one fact incriminated the subject and when these facts were interpreted by the investigators as evidence of the subject's involvement in the murder (as perpetrator or at least accomplice). Such interpretation of the facts was also adopted by the people around the subject (friends, neighbours), and the members of the family of the missing or murdered person (some of them feared for their lives). A description of these circumstances may seem unnecessary, but they are an argument in support of the accuracy of polygraph examination even if the subjects are affected by the emotions caused by additional sources. They may contribute to the discussion of the emotional activation of the groundlessly suspected subjects.

\section{Case 1}

A man went missing in 1979. The residents of the village where he lived were convinced that he had been murdered by his friend. Their suspicions were not altogether unjustified, as on the critical night the two men were drinking together in the sus- 
pect's house. Next day in the morning, being a farmer, the suspect went to his fields in a horse-drawn cart. The neighbours interpreted these facts in the following way: the men got drunk, had an argument and a fight, one hit the other too hard and killed him. On the next day, the 'perpetrator' moved the body away and buried it in the forest or in a field, or threw it into the bog. The missing man's friend had no motive - on the contrary: they were both soldiers in the same unit during the Second World War. There were no witnesses because both men were widowers. The villagers were so positive in their conviction that they threatened to lynch the man they suspected. He took the threats seriously and wanted police protection, demanding that they lock him up in a local jail. Apart from the slander, there was no other basis for charging and arresting him.

I prepared two CQTs and two SPOTs. The first SPOT was concerned with the date, or more precisely with the day when the two men last met, while the other focused on the way of disposing of the body.

The test concerning the day of the last meeting consisted of naming the days of the week from Monday (question 1) to Friday (question 5).

The subject claimed that his friend went home late on Tuesday evening, after they had had their drinks. In the test, Tuesday was marked as No. 2. The neighbours believed that he had disposed of the body on Wednesday, i.e. on the day following the drinking night (question No. 3). A reaction to the question No. 3 (Wednesday) would have meant that the subject had seen the missing man a day later than he had declared, i.e. he would have been lying about essential circumstances of the case.

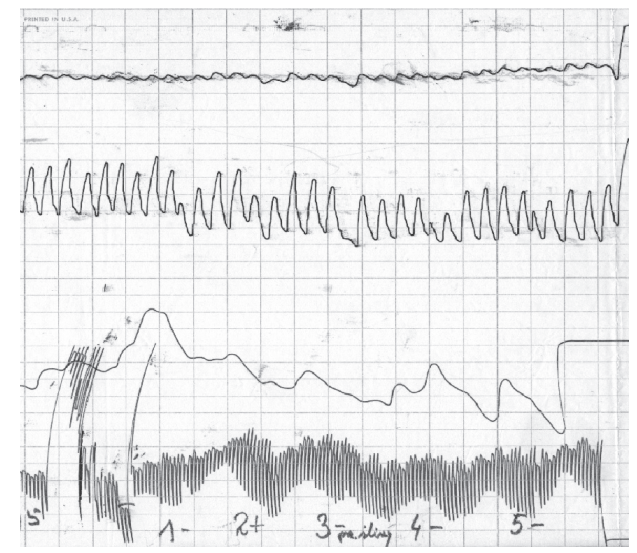

Fig. 1. The SPOT chart for the day of the last meeting. The answer to the question No. 2 was 'yes', but no changes in the parameters indicating a lie were recorded (only blood pressure was slightly increased). There was no reaction to the question No. 3, but there was an external manifestation of emotions - difficulties in swallowing. I did not repeat the test. The subject's pulse rate was over 110. 
The SPOT concerning the place where the missing man's body might be had six options.

1. Did you bury your friend's body in the forest?

1. Did you bury your friend's body in the field?

3. Did you throw your friend's body into a river?

4. Did you throw your friend's body into a bog?

5. Did you hide your friend's body in your farm?

6. Did you cart your friend's body away with the manure?

If the man had hidden the body outside his farm, he should have displayed a reaction to question No. 6 (carting the body away) and to one of the questions from 2 to 4 . After the pre-test discussion of the test questions, the subject said that his friend must have been going along the river on his way back and, being drunk, he probably slipped (it was the beginning of winter and the ground was very slippery) and fell into the water. It was the question No. 3. The man declared that he will also say 'no' to this question, because he could not be sure that this was what had really happened.

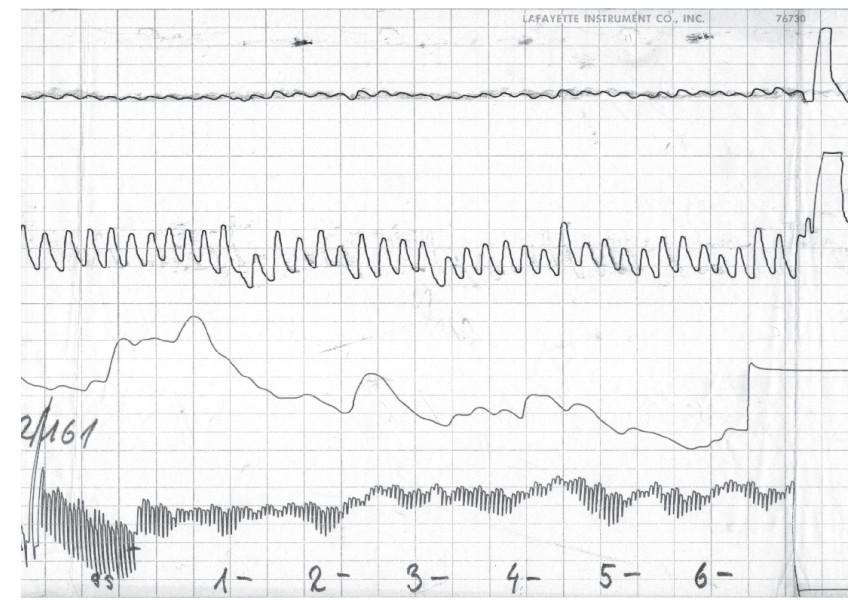

Fig. 2. The first SPOT chart concerning the manner of disposing of the body.

The most visible changes in the chart follow question No. 3. The parameters of the blood system show high general activation: high diastolic pressure (small cardio amplitude) and fast pulse rate (95-102). However, there were no reactions to the options considered as more probable (burying the body in the field, burying it in a forest, throwing it into a bog). 


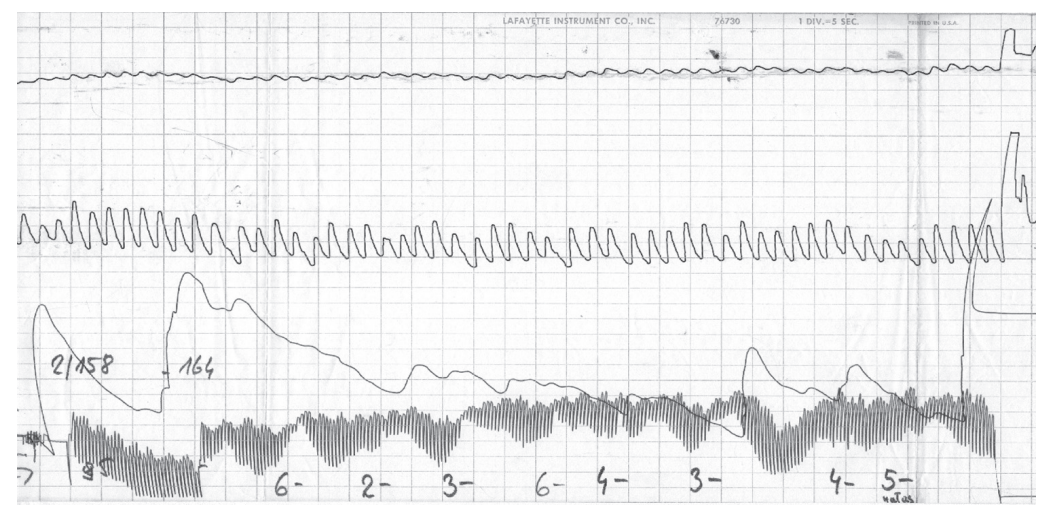

Fig. 3. The second SPOT chart concerning the way of disposing of the body.

In the second chart, the relatively largest changes (in the GSR and blood pressure) follow question No. 3. The subject reacted thus to the option he considered the most probable, and therefore his reaction was of no diagnostic value. Most importantly, there were no significant reactions to the questions concerning carting the body away and the manner of hiding it, which were suggested by the villagers in their testimonies (burying it in the field, burying it in a forest, throwing it into a bog). Secondly, the decrease of general level of activation in comparison to the first test chart is diagnostically significant: a decrease in the diastolic pressure (increase in the amplitude of the blood pressure tracing) and slowing down of the pulse (pulse rate was 100), especially well visible in comparison with the first SPOT chart. Only the depth of the breathing changed.

The parameters recorded in the first CQT chart testified to the subject's great emotional activation (considerable changes in the diastolic blood pressure and the GSR), but the reactions to the relevant and control questions were the same. In the consecutive charts, the diastolic blood pressure decreased as did the GSR reactions. The reactions following the relevant questions were not greater than those following the control questions. The subject also reacted strongly to all the neutral questions. These parameters spoke to the subject's advantage - it was hardly possible that he had committed a murder.

The analysis of the second SPOT chart proved that the subject's activation decreased. The test's tracings were essential for the final diagnosis. In both the techniques applied (CQT and SPOT), the general emotional motivation decreased. Considering the subject's critical situation (fear of the neighbours' revenge), this had an additional diagnostic value and spoke in favour of the opinion ruling out the version according to which he had committed the murder. 
The results of the examination were confirmed a few days later, when the body was found in the river and the autopsy showed that the victim was alive when falling into the water. The cause of death was drowning. The body carried no traces of injuries that may have caused death, no traces of battery, while there were substantial amounts of alcohol in the blood. The prosecutor dismissed the case.

\section{Case 2}

The charts of three people involved in the case of a 15-year-old girl who went missing in the summer of 1991 constitute an argument in support of the significance of the SPOT in inferring about a person's involvement in a murder. The girl lived with her parents and a younger brother in a village. On the critical day, she went on a bicycle ride and never came back. The search for the girl lasted for over 8 months, but neither she nor the bicycle were ever found. Some villagers claimed that the girl's mother cheated on her husband and suggested that because of that the girl and her mother had had a violent argument. They said that the girl had been beaten by her mother or her lover, who later hid the body and the bicycle. The police officers were so persuaded by this version that they wanted to arrest both of them after the polygraph examination. The girl's father also underwent the examination because of a guess that he might have agreed to an illegal adoption of the child by people living abroad. The fourth subject of the examination was the owner of the neighbouring house, who was suspected of raping and killing the girl.

I examined the subjects about 9 months after the event. Apart from the CQT, I applied several SPOTs. The CQT charts have been presented in another article, where I did not include the SPOT charts (Jaworski 2004).

During the pre-test interview the girl's mother said that she was convinced that her daughter was alive and would soon be found. She admitted that she was depressed because of the suspicions surrounding her and the gossip her friends and neighbours had been spreading. Her declaration could be as much true as it could be false - it could have been an attempt to justify her reactions during the tests.

She did not react to the relevant questions in the CQT or in the second and third CQT charts. Additionally, general physiological parameters showed a considerable decrease of general activation in the consecutive charts: decrease of the diastolic pressure and slower pulse rate. Following the CQT, I applied three SPOTs, each of which was repeated once. The first SPOT was concerned with the way of disposing of the 
girl's body, the second with the way of hiding the bicycle, while the third was concerned with the name of the perpetrator or accomplice.

Was the girl's body:

1. cremated?

2. drowned?

3. buried?

4. covered with dirt?

5. hidden in a rubbish dump?

6. hidden in the forest?

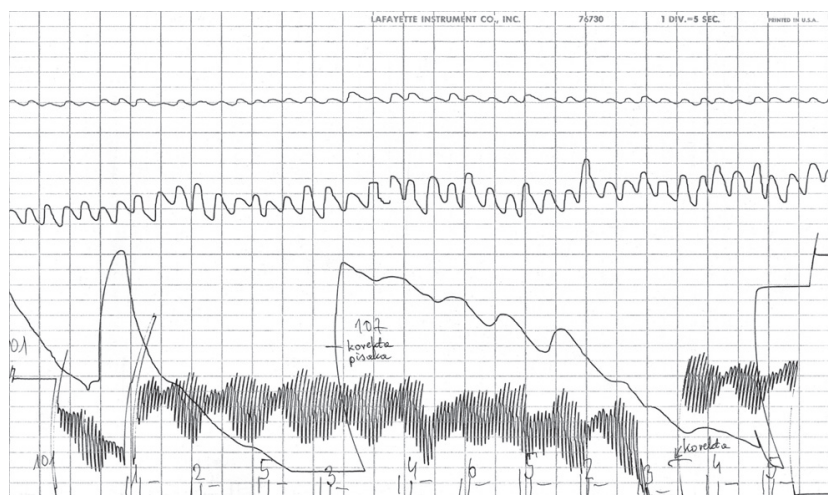

Fig. 4. The examination of the mother suspected of murdering her daughter. The first SPOT chart concerning the way of hiding the body. The test questions present six options.

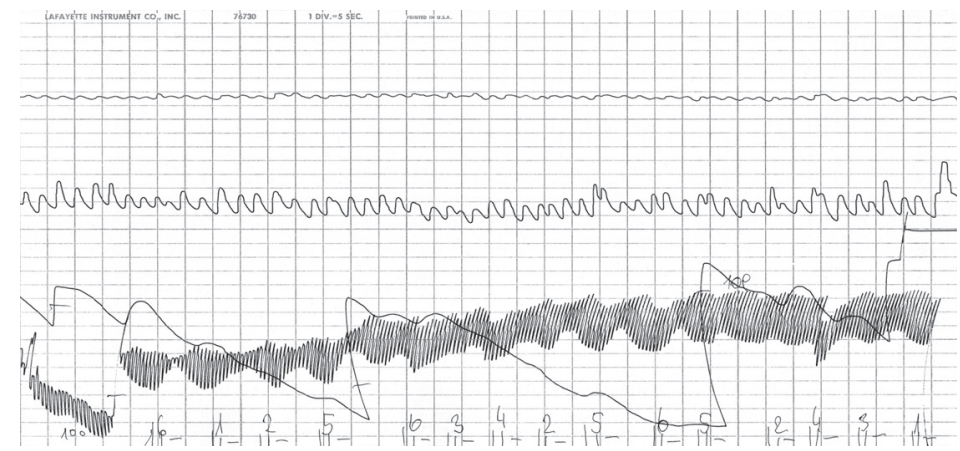

Fig. 5. The examination of the mother suspected of murdering her daughter. The second SPOT chart concerning the way of hiding the body. 
In both charts of the test, there are no reactions to one question. The pulse rate was relatively high (over 100 in the first SPOT, and below 100 in the second SPOT). However, two parameters, namely the great amplitude of blood pressure and the sharply decreasing GSR tracing, show that the general emotional activation decreased in either chart. The tendency intensified when the test was repeated. All this proves that the subject did not feel threatened by the issues covered in the test. The test charts prompt the conclusion that she did not hide her daughter's body.

The above requires a general remark: the questions in the test were not formulated correctly, as some had very similar content. The word 'buried' approximates the meaning of the phrase 'covered with dirt', while the next two 'hiding in the rubbish dump' and 'hiding in the forest' might consist in burying the body in these places, for which reason two separate tests should have been prepared. One should have focused on the way of disposing of the body: burying, covering in concrete, sinking, burning. The number of options at the disposal of an ordinary person is limited; it increases in the case of organised crime, when more 'sophisticated' methods can be used: dissolving in acid or another chemical substance, destruction with the use of lime (I have seen such cases in my practice). The other test should have focused on the place where the body might be, but determined geographically: a residential building, farm outbuildings, somewhere in the fields, a forest or more unusual places like a lake, gravel pit, rubbish dump, etc.

The content of the questions in both tests must take into consideration the geographical features of the area, e.g. whether in a city or in the country. Some ways of hiding the body are impossible in densely built-up areas. Preparation of the test should take into account whether the subject had access to a car or indeed owned one, which gives them a better opportunity of transporting the body and thus offers more options of disposing of it.

Further on during the examination two charts of the test concerning the place and manner of hiding the bicycle were administered. There were eight options. In the first chart there were no reactions to any of the questions.

Considerable changes in the galvo tracing following the questions Nos 6 and 7 are visible. I decided that they were coincidental, because they did not appear when the questions were asked for the second time. Moreover, there were no changes following the questions Nos 6 and 7 in the first chart of the test. Halfway through the test, the woman's emotional activation visibly decreased: the amplitude of the blood pressure tracing increased, and the GSR tracing distinctly decreased. The pulse rate was 95100 , i.e. quite high. 


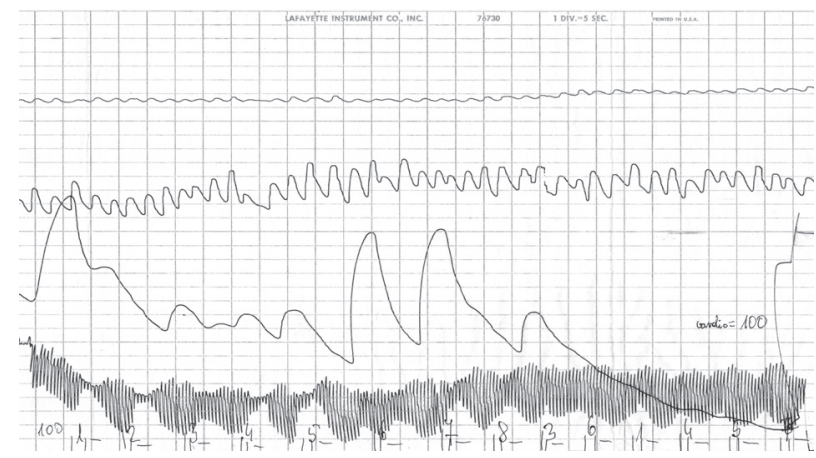

Fig. 6. The examination of the mother suspected of murdering her daughter. The second SPOT chart concerning the way of hiding the body. The questions were repeated.

The next SPOT was concerned with the name of the potential murderer. It included seven names. The question No. 3 featured the subject's name, the question No. 6 featured her lover's name. The reaction to question No. 3 would have had a diagnostic value, because it might have been caused by the syndrome of being 'groundlessly accused'. If, however, the reaction to the question No. 6 had been greater than that to the question No. 3, it could not have been a coincidence. The question No. 3 played the role of a particular 'comparison' question in relation to the question No. 6.

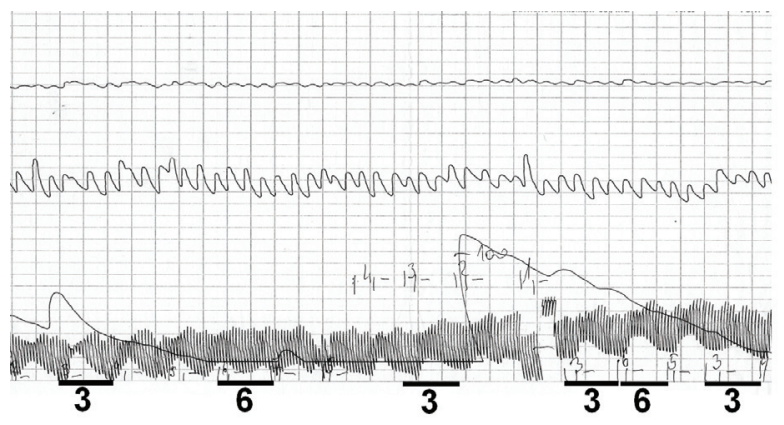

Fig. 7. The examination of the mother suspected of murdering her daughter. The SPOT chart concerning the name of the potential murderer. The woman reacted neither to her own name nor to the name of her lover (question No. 6).

This chart shows that the subject's breathing was irregular. All the remaining parameters indicate that general emotional activation decreased: the amplitude of the blood pressure tracing increased, the GSR tracing shows the tendency to decrease. The pulse rate is $95-100$. 
The analysis of the CQT test proves that she was not involved in the girl's disappearance and the SPOT proves that she did not know the key details of the event (the place(s) where the body and the bicycle had been hidden), the "knowledge of the perpetrator' test reveals no reaction to the name of a possible perpetrator (or coperpetrator) and to her own name.

The issues with which all the tests were concerned were quite drastic for the subject, not only because of the way the questions were formulated with all the suspicions focused on her, but also because throughout the polygraph examination the woman was convinced that her daughter was alive and would be found. The relevant questions in the CQT and the issues covered in the SPOT could potentially shatter her hopes and thus the tests could have caused strong emotions. Yet, the physiological parameters shown above indicate to the contrary as they show a decrease of emotional activation, therefore the woman did not perceive the test questions as a source of threat. I stated in the expert opinion that the combined analysis of the CQT and the SPOTs rules out the woman's participation in the murder.

The subject's pulse rate in the presented charts is quite high (about 100), approximating that of the perpetrators. It decreases in the consecutive charts but only insubstantially. The diastolic blood pressure in the second SPOT chart decreased distinctly. In this respect the difference between the subject's chart and those of the perpetrators is significant. There is also a great difference in the GSR tracing between the woman and the perpetrators.

\section{Examination of the lover of the missing girl's mother}

The man was the mother's lover and their relationship may have caused the quarrel between the girl and her mother. The prosecutor adopted the view that the man had cooperated with the woman, at least when hiding the body. Apart from the CQT, I administered two SPOTs (hiding the body, hiding the bicycle), where the questions were the same as in the woman's case.

In the first chart of the test concerning the body, the subject did not show any reactions to any options named in the test.

There are no reactions to the options formulated in the test questions in the second chart. Only at the beginning of the test there were there irregular changes in blood pressure. The remaining parameters testify to the decrease of emotional activation: a constant decreasing tendency of the GSR tracing, regular breathing, at the end of 
the test the diastolic pressure decreases. These parameters prove that the test questions do not cause any emotions in the subject. On the basis of the charts, I concluded that it was hardly possible that the man had anything to do with hiding the girl's body.

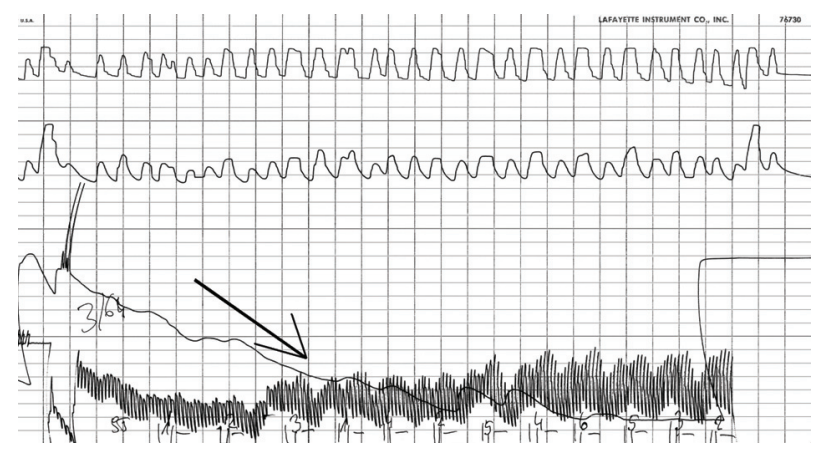

Fig. 8. Examination of the mother's lover - the alleged co-perpetrator in the murder of a girl. The second SPOT chart - the place where the body was hidden.

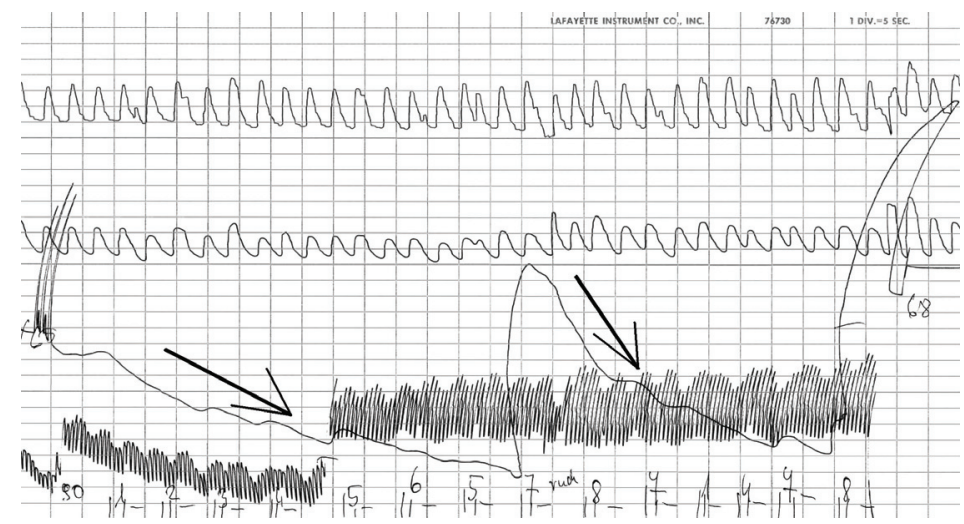

Fig. 9. Examination of the mother's lover - the alleged co-perpetrator in the murder of a girl. The second SPOT chart - the place where the bicycle was hidden.

Physiological parameters in both SPOTs prove a continuous decrease of the subject's emotional activation: the breathing is rhythmical and of constant depth, the amplitude of blood pressure is high, and the GSR tracing tends to decrease.

Evaluation of the SPOTs: if the subject had been the murderer, he would have known the details of the event formulated in the questions. If the girl's mother had been the perpetrator, considering the lapse of time after the event, she would have spoken about the event and then the subject would have known the places where 
the body and the bicycle had been hidden. He would not have been able to suppress the activation caused by the issues covered in the tests, even if the questions had not mentioned the actual places where the body and the bicycle had been hidden. His participation in the murder of the girl had to be ruled out.

The subject's pulse rate in the SPOT charts was over 90, decreasing to 90 in the last test. The value is quite high, approximating the pulse rate of the perpetrators. The difference in the blood pressure tracing is distinct; in the innocent person it decreases distinctly, especially the diastolic pressure. There is a great difference in the GSR tracing between the innocent and the perpetrators.

The accuracy of polygraph examination is assessed almost solely in relation to individual subjects. Yet, in my opinion in the cases when two or more people are suspected of cooperating in committing a crime, it is justified to carry out a combined analysis, consisting of an assessment whether there is a correlation between the content of relevant questions and the subjects' reactions to them. In the discussed case, I presented a combined opinion stating that the girl may have been murdered by two people:

'If it is assumed that one of the two co-murderers could hide emotions or control the physiology, it is almost impossible that both were able to do that. Theoretically possible but hardly probable in the case of one person, it is impossible that two people assumed to have cooperated in committing the murder display light and weaker reactions to relevant questions than to control questions. It is also virtually impossible that their general activation would decrease during the examination. 'Controlling' such parameters is difficult and hardly probable. This may be accomplished by one person, but it requires knowledge and the subject would have had to be trained in 'cheating' the polygraph. The situation that both potential co-perpetrators possessed such characteristics letting them simulate emotions or control their physiology may practically be excluded'.

This opinion surprised the police and the prosecutor as it defied the hypothesis which they considered certain. Yet, the prosecutor accepted the results of the examination and decided not to arrest the mother and her friend. The police did not accept the opinion so unequivocally favourable for the subjects and still looked for the evidence incriminating the woman and her lover. 


\section{Examination of the neighbour of the girl's parents}

The CQT and SPOT were also administered to the neighbour of the girl's parents. When formulating the CQT questions, I adopted the gravest hypothesis, i.e. murder. In two charts the man's reactions were stronger to the control questions than to the relevant questions, including the question 'Did you kill the girl?'. At the same time, his general emotional activation increased in the second chart (the diastolic blood pressure increased considerably, there was smaller blood pressure amplitude), and the breathing tracing was extremely distorted. During the test his face was red (Jaworski 2008). After the second CQT chart, I administered the SPOT concerned with the place and the manner of hiding the body (the same questions as in the test administered to the girl's mother).

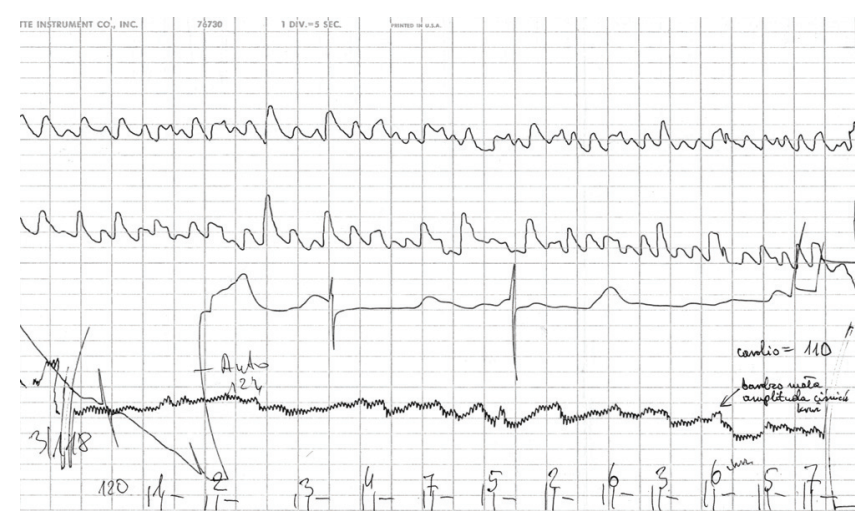

Fig. 10. Examination of the neighbour of the girl's parents. The SPOT chart (place of hiding the body). The test featured 7 options. GSR tracing in the automatic mode.

During the SPOT (hiding the body) the amplitude of the blood pressure was minimal and breathing was very irregular. The parameters prove that even though none of the options named in the test directly activated him, the problem formulated in the test caused very strong emotions.

After that test, the subject refused to take part in the examination, so I was unable to repeat that test as well as the CQT in the 'mixed questions' version. The subject's pulse rate was the fastest of all the examined people -110 beats per minute. Out of the four examined people, only his results were incriminating, even though there seemed to be no objective reasons for his anxiety. The SPOT was of utmost diagnostic significance in formulating the final expert opinion concerning the subject, considering that in his CQT the reactions to the control questions predominated - 
the test revealed that the man was strongly activated by the issue of hiding the body. I formulated it in the following way in the expert opinion: 'a person emotionally uninvolved with the issues formulated in the tests displays opposite proportions of reactions after control-stimulating tests. The examination itself could not have been a source of activation for Z.P. (the neighbour of the girl's parents) because the greatest irregularities would have occurred in the first chart and would have decreased in the consecutive ones. The subject's reactions are to the contrary: after he had realised that the examination was effective, he became even more activated'.

The opinion, however, was ignored by the police and the prosecution. That man was never interrogated. If he had been interrogated immediately after the polygraph examination, he would probably have revealed what he knew about the case, the perpetrator would have been apprehended sooner and additional incriminating evidence would have been discovered.

Even though the polygraph examination ruled out the woman's involvement in the murder, the police still suspected her. A few months later, when the girl's body was eventually found, they showed it to her, claiming that she should identify the corpse (which was unnecessary because a court-appointed doctor had already identified the girl on the basis of her teeth). In fact, they expected a psychological effect resulting in her confession. On showing the body, a police officer officially charged her with the murder of her daughter but the prosecutor dismissed the charges. In fact it was a case of persecuting an innocent woman.

Failing to interrogate the neighbour and charging the victim's mother with murder (despite the fact that such a hypothesis was ruled out by the CQT and SPOT) proves how ignorant the police officers and the persecutor were about polygraph examination. They found the gossip spread by the residents of the village more credible.

The line of the investigation changed only after an accidental discovery. The real perpetrator underwent polygraph examination, confessed to the murder, and was convicted (Jaworski 2004). He said that he had been walking along a dirt path in the forest when the girl had unexpectedly run into him on her bike. He had pushed her and she had hit her head against a tree. She showed no signs of life and he decided to hide her body. He went home to get a spade and returned to the forest to bury her. He passed by the garden of the girl's parents' neighbour at least twice. It was then that the neighbour must have seen him. The perpetrator's confession confirms the result of the neighbour's examination: he must have linked the missing girl with the strange 'saunters' of the young man who he knew between the forest and the house 
(the search for the girl began on the day when she went missing). The neighbour guessed who had killed the girl and where and how he had disposed of her body. The perpetrator said that he had hidden the bicycle in the forest but it was never found.

It is doubtful whether the neighbour's chart should be presented together with the charts of the other innocent people. He was 'innocent' in terms of the suspicion of murder. His reactions in the CQT suggested that the hypothesis was wrong (the reactions to the control questions were greater than those to the relevant questions). However, other factors indicate that he was indirectly involved in the event: he knew who the murderer was and concealed that knowledge. The factors include physiological parameters recorded in two CQT charts (the gradually increasing diastolic blood pressure and the degree of disorder in the rhythm and depth of breath). The disorders reach the maximum in the SPOT tracing presented above (this tendency was contrary to the tendencies present when the victim's mother was examined. They also include external manifestations of emotions, which, however, cannot be verified objectively. The conclusion that the subject's emotions increased is confirmed by his behaviour: a refusal to take part in the rest of the examination after the first SPOT.

The assessment of the increase of the subject's emotional activation contributed to the accuracy of the expert opinion: in the consecutive charts the diastolic pressure increased, the rhythm and depth of breathing also increased and the external manifestations of emotions intensified. These features prevented ruling out the subject's involvement in the murder. In my opinion the evolution of physiological parameters in the consecutive test charts is underestimated in the numerical analysis of the charts.

It is worth noting that the case discussed above proves that a holistic assessment of charts is more accurate than numerical one: if the numerical assessment consisted solely of the comparison of the proportions between the reactions to the relevant and control questions, the subject would most likely have been diagnosed as NDI, because the reactions to the control questions were greater than those to the relevant ones.

The previous article proposed the hypothesis that the SPOT greatly affects the perpetrators' emotional activation, while the discussed case proves that the tests cause strong emotions also in the people indirectly involved in the event, i.e. witnesses. The diagnostic significance of this fact is exceptionally important when we consider the claims of the opponents of the polygraph (and especially of the CQT) that the reactions to the relevant questions predominate in innocent subjects. 


\section{Case 3}

I applied the 'knowledge of the perpetrator' test when I examined three people suspected of attempted murder of a sentry. The sentry survived the attack but his gun and ammunition were stolen. The implement used in the assault was found nearby (it was used in the visual SPOT). According to the victim, there were two attackers familiar with military slang. Thus the adopted version assumed that the attacker was a soldier who cooperated with another soldier from his unit or a civilian acquaintance from the nearby town. There were a handful of indisputable facts that incriminated the suspected soldier.

The polygraph examination was administered to the suspect and his two most probable accomplices. Apart from the CQT, a visual SPOT (implement) as well as the SPOT with the names and nicknames of the subject's several friends were applied. In the CQT everyone reacted to the control questions and in the SPOT no-one reacted to the critical question. There were no changes in the test chart, therefore I did not repeat it. This decision was also influenced by the earlier results of the CQTs and the absence of reaction in the SPOT when the implement was shown.

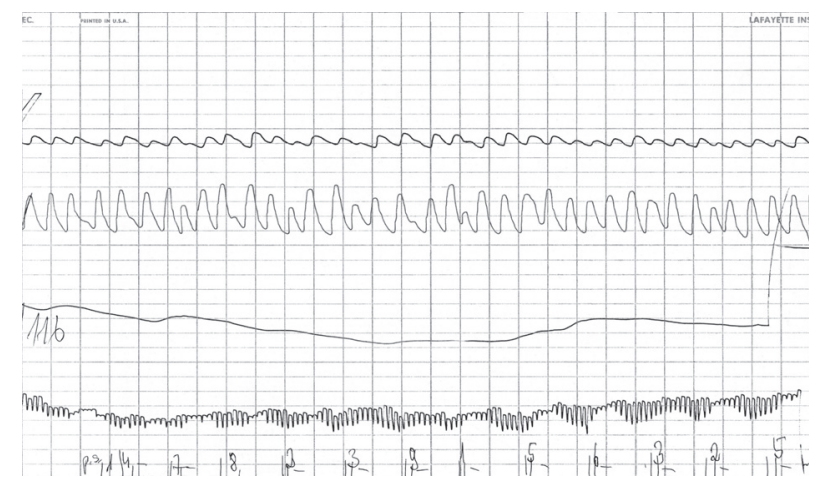

Fig. 11. Examination of the main suspect. The chart of the SPOT with the names of the probable accomplices in the assault on the sentry. There are no reactions to the names featured in the test, including the subject's own name - No. 3 .

For all the subjects, the SPOT charts were similar to the one presented above - there was no reaction to the names or nicknames featured in the test. Physiological parameters proved that the subjects were not exactly activated emotionally: the pulse rate did not exceed 80, there were no disturbances in the rhythm and depth of breathing, neither were there any changes in the blood pressure. 
The prosecutor was convinced that the facts incriminating the suspected soldier were obvious. He did not accept the result of the polygraph examination and claimed that the soldier was the perpetrator, but that he had simply managed to cheat the polygraph expert. The prosecutor demanded that the examination be repeated. The suspect agreed and I repeated the examination, modifying the questions to reduce the effect of habituation. In the second chart, the subject's reactions to the control questions were the same as those to the relevant questions. The subject's involvement in the event had to be ruled out.

The military police officers were more positive about the test results and they adopted another theory, which also involved the soldiers who had already completed their military service. The military police also analysed police reports, looking for the events where the perpetrators had used the type of gun that had been stolen. After a few weeks, they discovered a series of attacks on car drivers who were robbed of their money under a threat of a gun. Several victims described the attackers and their identikit portraits were made. One of them corresponded to the description of a soldier who had done his military service in the unit in question. It also turned out that he was wanted by the police for murdering two people. Although, after collecting a great deal of money, the criminals escaped abroad, they were eventually arrested and convicted.

The polygraph examination confirmed its accuracy concerning the 'innocent' people suspected of an attempt of murder and robbery of a gun and incriminated by other serious circumstantial evidence. Accurate assessment of the examination results by the military police officers and the change of the line of reasoning as to who the perpetrator had been made it possible to determine the real perpetrators who by the way proved to be very dangerous criminals.

The CQT charts and the SPOT (presentation of the implement) did not confirm the examinees' involvement in the assault and their knowledge about the implement used by the perpetrator; therefore I resigned from repeating the SPOT. The SPOT was not very useful in the final assessment of the results of the examination of the individual subjects, but it was impossible to foresee that before the examination commenced. An opposite effect was expected due to the number and significance of the facts incriminating the main suspect (there were definitely two perpetrators).

The SPOT was not repeated, so we cannot assess whether at all or how the physiological parameters constituting the manifestations of emotions would have changed. They can only be compared with the average parameters. They approximated the 'resting' parameters (relaxation): pulse rate below 80, no changes in blood pressure, flat GSR tracing, uniform rhythm and depth of breathing. These parameters were completely different in the case of the perpetrators. 


\section{Case 4}

I applied the 'knowledge of the perpetrator' test when I examined people suspected of murdering a young girl in 1997. She was a member of a gang composed of youngsters, 19-25 years of age. The gang was led by two men, a Pole and a Ukrainian. Before she met her death, the woman was tortured, which proved that the perpetrators wanted something from her. The police assumed that gang leaders killed the woman because she was about to pass information concerning the gang's activity, probably documents and/or material evidence, to the police. According to the police, the gang smuggled stolen cars and/or illegal drugs from Poland to Russia and Ukraine, but in fact they smuggled anabolic steroids, which the police did not know. At that time, anabolic steroids were not considered pharmaceuticals in Poland, and their distribution was not punishable by law. Only several years later were they classified as prescription drugs available only at the chemist's with any other form of distribution illegal. Therefore, the term 'criminal gang' in this context is not correct from the legal point of view, but it corresponds to the hypothesis adopted by the police. The gang had a motive for murder, which was confirmed by the fact that the girl had been tortured. The Polish gang leader had an additional motive, because the victim was his girlfriend and he had an affair with another woman. Suspicions concerning the gang members intensified by the ostentatious way in which they secured their alibi: on the day of the murder, the gang visited a few bars in another town. The police assumed that visiting bars aimed at creating an alibi, so that one of the gang members could leave the company and slip away for a short period of time and kill the woman. Both gang leaders denied the charges, while all the remaining gang members unanimously testified that no-one had left their company. The decision to administer polygraph tests to everyone, i.e. 4 men and 3 women was reached. The examination was applied a month after the murder. A CQT was applied to all the subjects and an additional test based on Keeler's assumptions was applied to the two main suspects. A SPOT with the names (pseudonyms) of possible perpetrators, including the subject's name, was also applied to five people. It played the role of the 'comparison question': a reaction to one's own name is highly probable also in the case of an innocent person; however, if the subject had reacted more strongly to another name or pseudonym, it would have had great diagnostic significance, i.e. it could not have been an accidental reaction, which could be explained with the syndrome of a 'groundlessly accused' person.

The reactions to the control questions predominated in the CQT charts of all the subjects, which proved that they knew nothing about the event and the perpetrator. In the SPOT charts of four subjects there was no reaction to any names or pseudonyms; additionally, their parameters proved that they were not emotionally activated 
with the issues covered by the tests: their pulse rate was 80 cycles per minute and only in the case of one of the main suspects it was 90. The SPOT charts were an important reinforcement of the CQT results, because all the examined men took hormones (steroids), which may have affected their physiological parameters. This may have caused a risk of committing an error in the CQT, especially that I had never experienced such a case before. The men were body-builders and took steroids. They took part in illegal boxing matches in Ukraine. Their other source of income was selling steroids in Poland and Ukraine. I had to rule out that the subjects (including the Polish leader of the gang) had committed the murder or knew who the perpetrator was.

The charts of the other main suspect were an exception: his pulse rate exceeded 100 and in the CQT he reacted very strongly to the additional question No. 11: Do you know why the perpetrators did it? At the same time his reaction to control question No. 6 was decisively greater than that to relevant questions No. 5 and 3. This proportion was seen in two CQT charts. In the additional test based on Keeler's technique, the GSR tracing showed that he had reacted very strongly to the question No. 11: Did the perpetrators act on someone's orders? The test was administered without cardio tracing, because during the second CQT chart the subject complained about the pressure of the cuff (sic!). The second CQT test was interrupted after question No. 9. The remaining charts, including the SPOT, were administered without the cardio tracing (I did not record the blood pressure).

During the test the subject displayed external manifestations of emotions: his face was red, he bit his lips and closed his eyes.

The expert opinion concerning the examination of this man was as follows:

'This subject is not a direct perpetrator but it was he who ordered the murder (possibly not confiding in his friend). He did not contact the perpetrators but their boss, therefore he does not know their names and appearance. If he knew them, the reaction to question No. 3 in the control questions test would have been much stronger'.

The polygraph examination was very helpful in resolving the case; firstly, it ruled out an almost certain hypothesis that the suspects were directly involved in the murder. Secondly, it revealed a new fact: the role of one of the subjects as the person who had arranged for the murder to be committed. This role of the suspect was substantiated by the following parameters:

- the repeatable and strong reaction to the additional relevant question No. 11 in the CQT, 
- in the R-I test, reaction to a similar question as the question No. 11 in the CQT,

- absence of reaction to his own name in the SPOT.

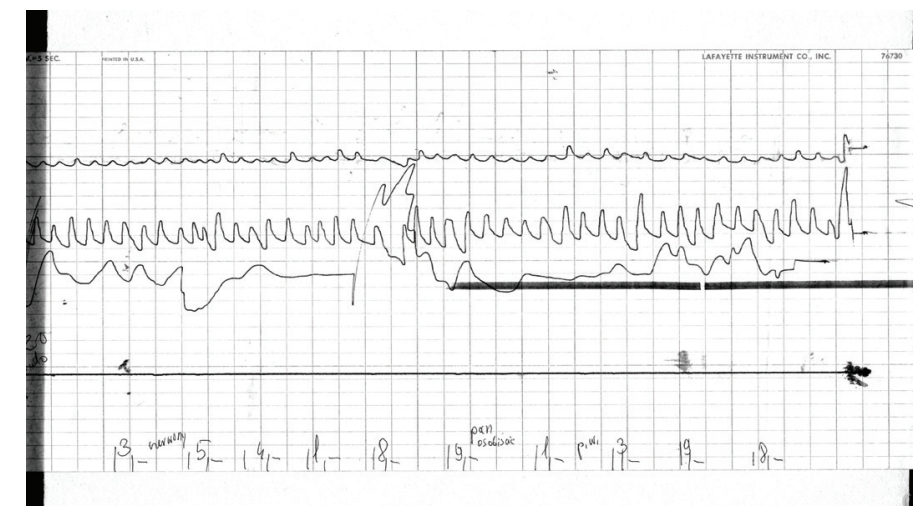

Fig. 12. The examination of the subject suspected of murdering the woman. The SPOT chart concerning the possible murderers. The GSR tracing in the automatic mode. The subject's name is at No. 9. The movement of the pen following name No. 8 is untypical (it is preceded by a peak, which is not the subject's natural physiological reaction). The peak was caused by a movement of the fingers or one deep breath. The reaction did not repeat after the name was repeated further on during the test. Notes: czerw. at the beginning of the test - reddening of the face; p.w. - biting of the lips. The pulse rate is undetermined, in the first CQT it was 102.

From the legal point of view, the person instigating a murder is liable to a more severe punishment than the actual murderer. However, the opinion of an expert is not the same as legal assessment, and the prosecutor did not charge the suspect, only incriminated by the result of the polygraph examination, with instigating murder. It is also worth noting that even though the suspect's reactions were strong and repeatable, they occurred only in one parameter (GSR) and in the external manifestations of emotions. The latter, however, are subjective and cannot be verified. It would be unrealistic to expect that a prosecutor would treat them as the solid basis for formulating the charges.

The chance of identifying the possible murders was low, because almost certainly they were Ukrainians - the suspect's friends. The suspect was a foreigner (Ukrainian). At that time, there were many citizens of the former Soviet Union in Poland. Some formed gangs involved in stealing and smuggling cars, robbery, and extortion. The Polish police did not have a good insight into the activities and composition of the groups, especially that they often changed their places of residence and travelled between the countries. Before the polygraph examination the hypothesis that such people could have been involved in the murder had not been considered. Their names or pseudonyms were unknown and they could not be featured in the SPOT. They had enough time to leave Poland between the murder and the apprehension of the sub- 
ject. There were no traces enabling identification of the perpetrators in the place of the crime. The prosecutor did not dismiss the case but suspended the investigation.

This test chart causes the same doubts as one of the cases discussed above - it is presented in the group of the 'innocent', because the subject was suspected of murder (this was formulated in the CQT: question No. 5). The examination ruled out this theory, but revealed another way of involvement, in this case: instigating murder.

There are also a few remarks exceeding the scope of this article, which nonetheless seem important from the point of view of the psychology of the emotions. The external manifestations of emotions (reddening of the face and biting the lips) - furthermore increasing during the examination - were of great significance in formulating the diagnosis. They proved that the subject reacted very emotionally. It might be expected that the emotions would have predominated over the subject's physiology and would have caused strong reactions to all the relevant questions in the CQT (this would be the argument of the opponents of the technique). The reactions did not occur, while the physiological parameters indicate to the contrary - the subject's reaction to the control questions were stronger. This case confirms the correctness of the assumptions of polygraph examination, because it shows that even great emotional activation does not prevent the possibility of finding out precisely which details of the case are the most important for the subject and which questions he or she perceives as the most threatening.

The subject displayed a reaction - quite strong - to only one of the relevant questions in the CQT. Its significance was objectively much lower than the 'strong' relevant question: 'Did you kill the girl?' The 'strong' question became a particular 'comparative' question due to its content, because it did not cause any reaction, while the theoretically 'weak' question No. 11 caused a very strong reaction (which justifies the name 'Comparison Question Test').

A standard comparison question test features only 10 questions, which includes 4 relevant ones. The relevant question No. 11 exceeded the regular CQT pattern, but it was this question that played the pivotal role in determining the subject's role in the murder. Four relevant questions cannot always comprise all the issues that might cause the subject's emotions. In reality the suspect may not be the perpetrator (relevant question No. 5) but a witness or an accomplice (relevant question No. 3), a receiver of stolen goods (relevant questions Nos 8 and 9) or an instigator of a crime. The investigators present their own theories about the subject's involvement in the event to the expert, but sometimes neither they nor the expert know what the real involvement was. The questions do not always cover the real role which the subject 
played during planning, preparing and executing the crime, and while removing the traces and disposing of the implements. If the test had followed the pattern to the letter (the usual number of questions), the examination result would have been positive for the man, who would have been excluded from the circle of suspects, while in reality he had instigated the murder.

\section{Summary}

The assessment of physiological parameters of the innocent subjects in the SPOT in the presented cases has its limits, while a comparison of these parameters with the charts of the perpetrators causes doubts as to the methodological soundness (lack of a sufficient number of cases). There are as many as four reasons hindering the assessment.

First of all, the number of presented charts of the innocent subjects is small; they are practically isolated cases and with tests featuring mainly names (given names, pseudonyms).

Secondly, I did not repeat the SPOT if it did not cause any reaction and at the same time the preliminary assessment of the CQT charts was positive for the subjects. This makes it impossible to compare physiological parameters of the subject in at least two SPOT charts in order to assess the evolution of the emotional activation. The parameters recorded during a SPOT were compared with the first CQT chart, but this article does not present them.

Another problem results from the fact that the category of the 'innocent' includes the charts of two subjects (the witness of the behaviour of the possible perpetrator after the murder and the instigator of a murder). I included them in the groups of the 'innocent' only because the version before the examination assumed that they were the murderers, while their reactions to the control questions in the CQT were greater than those to the fundamental relevant question ('Did you do it?'). As I mentioned above, physiological parameters of the two men in the consecutive CQT charts hinted at intensification of emotions and the subjects themselves also displayed external manifestations of emotions. In principle, their charts should be presented in the group of 'the perpetrators'. Although the manifestations of emotions were distinct, their assessment was subjective - and it cannot be verified. Both subjects interfered with the examination: one refused to have his blood pressure and pulse recorded and the other interrupted the examination. This behaviour is typical for 'the perpetrators'. Both subjects were involved in the cases, but not in the way the investigators 
had originally assumed. Let me add here that this is my opinion and it has not been backed by legal decisions.

Physiological parameters of the innocent subjects presented in the SPOT charts can only be assessed visually, because the Lafayette polygraphs which I used did not record them digitally. A visual assessment is not precise and to great extent subjective. Only one parameter - the pulse rate - lends itself to digital assessment, but with the reservations mentioned above.

\section{Physiological parameters of 'the perpetrators' and 'the innocents' in the SPOT} Pulse rate of the innocent subjects in the CQT and SPOT was higher than the resting rate (and much higher in two subjects: case 1 Kuczyński, ataman) but lower than that of the perpetrators. The pulse rate of all the innocent subjects was lower in the SPOT than in the first chart of the CQT (the SPOT was administered after the CQT).

Blood pressure: I estimate that the blood pressure of the innocent subjects was lower in the SPOT than in the first chart of the CQT (the diastolic pressure decreased). This was manifested by a greater amplitude of the tracking. When the SPOT was repeated, the amplitude increased further.

GSR: I was responsible for making the assessment of the GSR tracking more difficult, because I sometimes used manual recording and sometimes automatic. The manual recording seems more useful diagnostically, because the decreasing tendency of this tracking is convincing when the subject's level of activation is assessed (this was seen in the innocent people; however, the number of the tests is very small).

Breathing: depth of breathing and the proportions between individual instances of inhaling and exhaling as well as the rhythm of breathing seem to approximate the resting state.

Showing the differences between 'the perpetrators' and 'the innocents' in a methodologically correct way would require the digital measurement of the parameters, which is currently impossible.

It would be interesting to find out about the conclusions which other experts drew when administering the SPOTs, and especially their opinion about their actual significance and potential differences in the behaviour of the perpetrators and the innocent people. It would also be important to carry out experiments to verify the existing hypotheses, even though it would be difficult to acquire such a level of emotional activation which occurs in real perpetrators.

\section{Remarks on the structure of the SPOTs}

The presented examples confirm the correctness of the guidelines formulated in literature concerning the construction of the SPOT and the content of the questions. 
If the questions are not formulated according to the principles of logical division, the experts mislead themselves. The results were seen in the case described in the previous article (the tests concerned the manner of disposing of jewellery and clothes) and in this article in the test concerning the place of hiding the girl's body by her mother and the mother's lover.

When the cases of searching for bodies are concerned, it should be added here that preparing two tests (the first - the way of destroying or hiding the body; the other - geographical location of the place of hiding) would have an additional benefit, because the SPOT causes emotional activation of the perpetrators, which is precisely what I try to show. In some cases it is so great that they are induced to confess or behave in a way which unambiguously shows that they were involved in the murder. The change of priorities in the analysis of the SPOT which I propose is also well grounded in the case when the corpse is dismembered (several possible hiding places). The subject will probably react to at least two questions, but the issue will cause considerable emotional activation, which will increase when the SPOT is repeated. A greater number of tests of this type, when they are repeated, provides the expert with more diagnostic premises.

A significant difficulty may be caused by the cases of polygraph examination of the family members of the missing suspected of murder. The suspicion may be groundless, while the family members may be indignant about it and refuse to take part in the examination. The proposal to apply the SPOT may intensify their negative attitude to the examination (the family do not want to accept the fact of death, being convinced that the missing person is alive). In such a situation, the SPOT may be concerned with clothes or an object which the missing person had on him or her.

Every CIT or SPOT makes sense if it includes several (more than four) options. The problem with the tests concerning the problem of hiding the body also consists in the fact that sometimes only two options are real and it is difficult to think of any equally realistic ones. Some ways of destroying a body are difficult to implement: for instance, cremating a body requires very high temperatures, lasts a number of hours, and may be noticed by others because it causes a lot of smoke. In such cases, the APA's proposal concerning the content of the SPOT questions makes sense (Polygraph 2011), even though it may cause the doubts pointed out by Nakayama: the content of neutral questions is radically different than that of 'relevant' questions, and at least theoretically may cause a subject's reaction to probable items (Nakayama 2002). If the SPOT aims at the assessment of the evolution of emotional activation during consecutive tests, the reservations concerning the difference in the content of items are, however, of lesser significance. 


\section{References}

Federal Psychophysiological Detection of Deception Examiner Handbook, Polygraph 2011, Vol. 40, No. 1. Special Edition, p. 43.

Jaworski R., Evaluation of Polygraph Examination against a Background of its Evidential and Investigative Significance, Journal of Forensic Identification, 2004, 54, 4, 448-464.

Jaworski R., Multi-subject polygraph examinations, University Press, Wroclaw 2008, pp. 35-44.

Jaworski R., Observations from the Analysis of Searching Peak of Tension Test (SPOT) Charts, European Polygraph, 2015, 9, 1 (31), 25-54.

Nakayama M., Practical Use of the Concealed Information Test for Criminal Investigation in Japan [in:] M. Kleiner (ed.), Handbook of Polygraph Testing, Academic Press, 2002, London, p. 58. 
